\title{
Associated Factors of Bone Mineral Density and Osteoporosis in Elderly Males
}

\author{
Behzad Heidari, ${ }^{1}$ Abdollah Muhammadi, ${ }^{1}$ Yahya Javadian,, Ali Bijani, ${ }^{2}$ Reza Hosseini, ${ }^{2}$ and Mansour \\ Babaei $^{3, *}$ \\ ${ }^{1}$ Mobility Impairment Research Center, Babol University of Medical Sciences, Babol, Iran \\ ${ }^{2}$ Department of Social Medicine, Babol University of Medical Sciences, Babol, Iran \\ ${ }^{3}$ Department of Internal Medicine, Clinical Research Development Unit, Rouhani Hospital, Mobility Impairment Research Center, Babol University of Medical Sciences, \\ Babol, Iran \\ "Corresponding author: Mansour Babaei, Department of Internal Medicine, Clinical Research Development Unit, Rouhani Hospital, Mobility Impairment Research Center, \\ Babol University of Medical Sciences, Babol, Iran. Tel: +098-1132238301-5; +98-9113134249, Fax: +98-1132238284, E-mail: babaeim47@yahoo.com
}

Received 2016 June 01; Revised 2016 October 19; Accepted 2016 November 19.

\begin{abstract}
Background: Low bone mineral density and osteoporosis is prevalent in elderly subjects. This study aimed to determine the associated factors of bone mineral density and osteoporosis in elderly males.

Methods: All participants of the Amirkola health and ageing project cohort aged 60 years and older entered the study. Bone mineral density at femoral neck and lumbar spine was assessed by the dual energy X-ray absorptiometry (DXA) method. Osteoporosis was diagnosed by the international society for clinical densitometry criteria and the association of bone mineral density and osteoporosis with several clinical, demographic and biochemical parameters. Multiple logistic regression analysis was used to determine independent associations.

Results: A total of 553 patients were studied and 90 patients (16.2\%) had osteoporosis at either femoral neck or lumbar spine. Diabetes, obesity, metabolic syndrome, overweight, and quadriceps muscle strength $>30 \mathrm{~kg}$, metabolic syndrome, abdominal obesity and education level were associated with higher bone mineral density and lower prevalence of osteoporosis, whereas age, anemia, inhaled corticosteroids and fracture history were associated with lower bone mineral density and higher prevalence of osteoporosis $(\mathrm{P}=0.001)$. After adjustment for all covariates, osteoporosis was negatively associated only with diabetes, obesity, overweight, and QMS $>30 \mathrm{~kg}$ and positively associated with anemia and fracture history. The association of osteoporosis with other parameters did not reach a statistical level.

Conclusions: The findings of the study indicate that in elderly males, diabetes, obesity and higher muscle strength was associated with lower prevalence of osteoporosis and anemia, and prior fracture with higher risk of osteoporosis. This issue needs further longitudinal studies.
\end{abstract}

Keywords: Anemia, Diabetes, Elderly Males, Obesity, Osteoporosis, Obesity

\section{Background}

Bone mass decreases with aging and results in osteoporosis in elderly subjects. Low bone mass is an important public health problem in both aged females and males because of its consequent bone fractures and resultant morbidities, disability as well as social costs (1). Similar to postmenopausal females, osteoporosis is also prevalent in males and almost $25 \%$ of males older than 50 years old, will experience an osteoporotic fracture (2).

Bone mineral density (BMD) loss is an important contributor of fracture particularly in subjects aged 65 years and over (3). Mortality of hip fracture in males is two to three folds greater than in females (4). Only $21 \%$ of males with hip fractures can live independently in the community during the following year; other patients require home care or institutionalization (5). In elderly males, de- creased bone mass and increased risk of fracture have been attributed to low levels of sex steroids by aging, as well as age-related osteoblast dysfunction (6).

The results of a longitudinal study, over a 4.6-year follow-up period indicated that combination of low estradiol and low testosterone was associated with significantly faster BMD loss in males (7). The results of a systematic review of 55 studies showed that factors such as age, low body mass index (BMI), current smoking, excessive alcohol use, chronic corticosteroid use, hypogonadism, diabetes, prior fractures, history of falls and stroke, are risk factors of low bone mass in males (4).

Secondary causes of osteoporosis are also common, and in a study of elderly males and females the causes of osteoporosis were treatable in a significant proportion of patients (8). Several previously published studies have ad- 
dressed the causes of bone loss in elderly subjects (8-15). Nonetheless, the results of studies regarding the relationship between BMD changes and many associated factors especially obesity, metabolic syndrome and diabetes, varied across various studies (11, 12, 14-16). This issue may be attributed to characteristics of the study subjects, such as ethnicity, lifestyle, demographic features or study design. In addition, age, level of daily physical activities, education and serum vitamin D may differently affect the results across different study populations.

Contribution of the associated factors in the development of low BMD differs among various studies. In one study of community-dwelling white males, aged $>65$ years old, bioavailable testosterone accounted for $20.7 \%$, physical activity score for $9 \%$ and BMI for $6.5 \%$ of BMD variance (10). Awareness of the associated factors of bone changes in elderly patients is of particular importance because a number of risk factors can be treated or modified $(8,9)$.

Prevalence of osteoporosis in Iranian populations has been investigated in several studies but the results are conflicting (17). A number of anthropometric, nutritional and economical factors have been investigated and have concluded that in the Iranian population, BMD is lower than European and US populations due to differences in lifestyle, ethnicity, nutrition and anthropometrics (18).

We have shown the associated factors of osteoporosis in elderly females living in northern Iran (19) yet epidemiological data regarding the prevalence and the associated factors of BMD in elderly males are lacking. This issue justifies a study to address the associated factors of low BMD in older males. In particular, many clinical conditions such as diabetes, obesity, metabolic syndrome, and vitamin D deficiency, which diversely influence BMD, are highly prevalent in this area (20-24).

\section{Objectives}

The aim of this study was to determine the association between BMD as well as osteoporosis and several clinical, biochemical, and socio-demographic characteristics in elderly males aged 60 years and older. The study population consisted of all male participants of the Amirkola health and ageing project (AHAP) cohort (23).

Since the participants of this cohort had similar characteristics regarding ethnicity, nutrition, lifestyle, body habitus and socio-demographic features, the results of this study are expected to have a low level of bias.

\section{Methods}

The patients of this study were selected according to the inclusion criteria for male participants of the cohort of the Amirkola health and ageing project (AHAP). This project was conducted in Amirkola, Babol, a town located in the southern shore of the Caspian Sea, north of Iran. The project was funded by the vice-chancellery of Research and Technology, Babol University of Medical Sciences for investigation of geriatric medical problems such as falling, bone fragility and fractures, cognitive impairment and dementia, poor mobility and functional dependence. The baseline of this project was done during years 2011 and 2012. All inhabitants aged 60 years and over were invited to participate in this study and $72.3 \%$ of the invited subjects participated and completed the project (23). All male participants, who performed bone densitometry, entered the study. Individuals with acute or chronic inflammatory musculoskeletal diseases, systemic gastrointestinal, renal, respiratory diseases and patients, who were receiving anti-osteoporosis treatment and oral corticosteroids, were excluded. Informed consent was obtained from all patients and the proposal of this study was approved by the ethic committee of the Babol University of Medical Sciences, Babol, Iran.

Data were collected for age, marital status, smoking, prior history of fractures, taking medication such as calcium and vitamin D supplementation as well and inhaled corticosteroids, anti-osteoporosis treatment, occupation, educational level, physical activity, quadriceps muscle strength (QMS), BMI, hemoglobin, serum creatinine, calcium, phosphate, serum 25-hydroxyvitamin D concentration, ferritin, thyroid function test, testosterone and parathyroid hormone level(Table 1). The QMS was measured in both limbs by hand -helded dynamometry. In this method, isotonic knee joint extension was performed in a seated position against a fixed dynamometer which was positioned $5 \mathrm{~cm}$ above the lateral malleolus of the tibia. The average value of three measurements was considered for analysis. Details of the data collection and the specific methods for blood analysis have been described elsewhere (23). Osteoporotic fractures were confirmed based on selfreported data and medical records. Traumatic bone fractures were excluded. Diabetes was confirmed by history and fasting blood sugar measurement and metabolic syndrome was confirmed by ATP III criteria and abdominal obesity was confirmed by waist circumference $>95 \mathrm{~cm}$ (22). The BMD was measured in the lumbar spine (LS) at L2 - L4 regions and femoral neck (FN) by dual energy X-ray absorptiometry (DXA) method using the Lexxos densitometer. The precision errors of BMD measurements were $1.3 \%$ for total hip, $2 \%$ for femoral neck and $2.3 \%$ for spine. The results of BMD measurement were expressed as BMD g/cm², BMD T-score, BMD Z-score. Osteoporosis was diagnosed according to the International Society for Clinical Densitometry criteria defined as BMD values of 2.5 SD or more below 
the mean value for young adults (T-score $\leq-2.5$ ) at either FN or LS measurement sites (one diagnostic category) (25). The reference value for determination of T- score was provided by the manufacturer (Lexxos).

\subsection{Statistical Analysis}

In the statistical analyses, the proportion of osteoporosis at either FN or LS was determined and patients with and without osteoporosis were compared according to BMD parameters, frequency of clinical conditions, demographic and biochemical characteristics (Table 1). The correlation was determined using the Pearson test. Association was determined by chi square test by calculation of odds ratio (OR) with 95\% Confidence Interval (95\%CI). Multivariate regression analysis with simultaneous adjustment for all covariates (was used to estimate the independent association between osteoporosis and demographic, clinical and biochemical factors by calculation of adjusted OR (95\% CI). The SPSS software version 18 was used for the analysis.

\section{Results}

A total of 553 males with mean age of $70.0 \pm 7.7$ years were studied. Two hundred and twenty nine subjects (41.4\%) were $>70$ years old. Ninety out of 553 subjects (16.2\%) had osteoporosis at either LS or FN. Mean age of osteoporotic patients was significantly higher than those without osteoporosis (71.4 \pm 8.1 vs. $68.5 \pm 7$ years, $\mathrm{P}=0.001$ ).

The BMD gr $/ \mathrm{cm}^{2}$ at both measurement sites in patients with and without osteoporosis is shown in Table 2. As expected, all BMD parameters at both FN and LS were significantly lower in osteoporotic patients as compared with patients without osteoporosis. The magnitudes of FMBMD and LSBMD in osteoporotic patients were lower by $24.7 \%$ and $26.8 \%$, respectively (Table 2 ). History of fractures was found in 158 subjects with mean age of $68.2 \pm 7.16$ years. Subjects with fractures had significantly lower FNBMD and LSBMD but higher prevalence of osteoporosis (Figure 1).

Characteristics of patients with and without osteoporosis are presented and compared in Tables 1 and 2). In patients with osteoporosis, prevalence of diabetes, metabolic syndrome, general obesity and abdominal obesity was significantly lower and anemia was significantly higher ( $\mathrm{P}=0.001$, for all). Serum 25-hydroxyvitamin $\mathrm{D}$ in osteoporotic patients was non-significantly lower $(\mathrm{P}=$ 0.088). Prevalence of fractures in osteoporotic patients was significantly higher $(\mathrm{P}=0.004)$. Prevalence of subjects taking inhaled corticosteroid was higher and those with higher level of education were significantly less common amongst osteoporotic patients $(\mathrm{P}=0.004$, and 0.009 respectively) while patients with high level of physical activity and subclinical hypothyroidism (TSH > 5) were comparable in both groups (Table 1 ).

Biochemical parameters such as serum hemoglobin, iron and ferritin were significantly lower in patients with osteoporosis ( $\mathrm{P}=0.001 ; \mathrm{P}=0.009$ and $\mathrm{P}=0.036$, respectively). Serum creatinine, Ca, phosphate, uric acid, transferring, parathyroid hormone and testosterone, did not differ between the two groups. Serum 25-hydroxyvitamin $\mathrm{D}$ in osteoporotic patients was non-significantly higher ( $\mathrm{P}$ $=0.051$ ) and prevalence of 25-hydroxyvitamin D deficiency was non-significantly lower in osteoporosis $(\mathrm{P}=0.088)$.

There was a positive relationship between increasing age and prevalence of osteoporosis. Prevalence of osteoporosis increased from $13 \%$ in the age group of 60 - 69 years to $36.4 \%$ in patients aged 80 years and older $(\mathrm{P}=0.001)$ (data are not shown). Both FNBMD and LSBMD correlated negatively with age $(\mathrm{r}=-0.332, \mathrm{P}=0.001$ and $-0.133, \mathrm{P}=$ 0.001 ) (Table 3 ). In regression analysis compared with age group of 60 - 69 years, age of $>80$ years was associated with significantly higher risk of osteoporosis by OR $=2.15$ ( $95 \%$ CI, 1.009 - 4.59, P=0.045) (Table 4).

After adjustment for other confounders including age, metabolic syndrome, muscle strength, physical activity, educational level, history of fractures, abdominal obesity, smoking and other biochemical parameters (Table 1), the association between age and osteoporosis decreased to a non-significant level. Subgroup analysis demonstrated a similar distribution of general and abdominal obesity as well as metabolic syndrome across various age groups but the distribution of muscle strength was inversely correlated with age (data are not shown). Prevalence of muscle strength $>30 \mathrm{~kg}$ decreased by age from $61.7 \%$ in the age group of 60 - 69 years to $12.7 \%$ in the age group of $>80$ years $(\mathrm{P}=0.001)$.

Body mass index was positively correlated with BMD at both measurement sites. The magnitude of Pearson correlation coefficient for BMI and FNBMD was higher than BMI and LSBMD ( $\mathrm{r}=0.565$ vs. 0.383 ) (Table 3 ).

Compared with BMI $<25 \mathrm{~kg} / \mathrm{m}^{2}$, obesity (BMI $>30$ $\mathrm{kg} / \mathrm{m}^{2}$ ) and overweightness (BMI = $20-29 \mathrm{~kg} / \mathrm{m}^{2}$ ) were associated with lower risk of osteoporosis by OR $=0.20(95 \%$ CI, $0.11-0.36, \mathrm{P}=0.001$ ) and $\mathrm{OR}=0.29$ (95\%CI, $0.07-0.54$, $\mathrm{P}=0.001)$, respectively. After adjustment for the earlier mentioned confounders (Table 1), lower risk of osteoporosis remained at a significant level for obese and overweight cases $(\mathrm{OR}=0.21$ (95\% CI, $0.1-0.42, \mathrm{P}=0.001)$ and $\mathrm{OR}=0.25$ (95\% CI, 0.06 - 0.0.92, P = 0.038), respectively)(Table 4).

Diabetes was associated with significantly lower risk of osteoporosis by $\mathrm{OR}=0.35$ ( $95 \% \mathrm{CI}, 0.18-0.68, \mathrm{P}=0.001$ ) After adjustment for the mentioned confounders includ- 
Table 1. Comparison of Clinical and Biochemical Characteristics in Elderly Males With and Without Osteoporosis Recruited From the Amirkola Cohort Study ${ }^{\mathrm{a}, \mathrm{b}}$

\begin{tabular}{|c|c|c|c|}
\hline Patients Characteristics & Osteoporosis Present ${ }^{\mathrm{c}}$ & Osteoporosis Absent & PValues \\
\hline No. of patients & 90 & 463 & \\
\hline Age $^{\mathrm{d}}, \mathrm{y}$ & $71.4 \pm 8.1$ & $68.5 \pm 7$ & 0.001 \\
\hline Body mass index ${ }^{\mathrm{d}}, \mathrm{kg} / \mathrm{m}^{2}$ & $23.5 \pm 3.5$ & $26.6 \pm 3.9$ & 0.001 \\
\hline$<25$ & $67(74.4)$ & $154(33.2)$ & \\
\hline $25-29$ & $18(20)$ & $224(48.4)$ & 0.001 \\
\hline$>30$ & $5(5.6)$ & $85(18.4)$ & 0.001 \\
\hline Total physical activity score $^{\mathrm{d}}$ & $97 \pm 67$ & $110 \pm 69.8$ & 0.092 \\
\hline Quadriceps muscle strength ${ }^{\mathrm{d}}$,kg & $23.4 \pm 8.3$ & $30.1 \pm 3.9$ & 0.001 \\
\hline Education level, No. (\%) & & & 0.023 \\
\hline Illiterate & $62(68.8)$ & $258(55.7)$ & \\
\hline Primary school & $23(25.6)$ & $136(29.4)$ & 0.023 \\
\hline High school and university & $5(5.6)$ & $69(14.9)$ & 0.004 \\
\hline Inhaled/oral corticosteroid users & $11(12.2)$ & $23(5)$ & 0.009 \\
\hline Smokers & $30(33.3)$ & $157(33.9)$ & 0.916 \\
\hline History of fractures, $\mathrm{No}(\%)$ & $37(41.1)$ & $121(26.1)$ & 0.004 \\
\hline Vitamin $D^{\mathrm{d}}, \mathbf{n g} / \mathrm{mL}$ & $36.9 \pm 27.8$ & $30.7 \pm 25.4$ & 0.051 \\
\hline$<20$ & $28(31)$ & $164(35.4)$ & \\
\hline $20-20$ & $27(30)$ & $172(37.2)$ & 0.088 \\
\hline$>30$ & $35(38.9)$ & $127(27.4)$ & \\
\hline Hemoglobin $^{\mathrm{d}}, \mathrm{gr} / \mathrm{dL}$ & $13.7 \pm 1.4$ & $14.5 \pm 1.4$ & 0.001 \\
\hline Serum creatinine ${ }^{\mathrm{d}}, \mathrm{mg} / \mathrm{dL}$ & $1.002 \pm 0.22$ & $1.03 \pm 0.22$ & 0.266 \\
\hline Serum Iron $^{\mathrm{d}}, \mu \mathrm{g} / \mathbf{d L}$ & $80.8 \pm 33.7$ & 91.437 .4 & 0.009 \\
\hline $\operatorname{TIBC}^{\mathbf{d}}, \mu \mathrm{g} / \mathbf{d L}$ & $282 \pm 46.6$ & $278 \pm 42$ & 0.404 \\
\hline Serum ferritin $^{\mathrm{d}}, \mathrm{ng} / \mathrm{mL}$ & $143.4 \pm 106$ & $171.3 \pm 116$ & 0.036 \\
\hline Serum calcium $^{\mathrm{d}}, \mathrm{mg} / \mathrm{dL}$ & $9.2 \pm 0.42$ & $463 \pm 9.2$ & 0.611 \\
\hline Serum phosphate $^{\mathrm{d}}, \mathrm{mg} / \mathrm{dL}$ & $3.9 \pm 0.63$ & $3.8 \pm 0.59$ & 0.063 \\
\hline Parathyroid hormone ${ }^{\mathrm{d}}, \mathrm{pg} / \mathrm{mL}$ & $53.9 \pm 38$ & $53.9 \pm 40$ & 0.99 \\
\hline Serum Testosterone $^{\mathrm{d}}$, ng/dL & $4.3 \pm 3.5$ & $4.8 \pm 4.4$ & \\
\hline Diabetes, No. (\%) & $11(12.2)$ & $131(28.3)$ & 0.001 \\
\hline Metabolic syndrome, No. (\%) & $42(46.7)$ & $325(70.2)$ & 0.001 \\
\hline \multicolumn{3}{|l|}{ Serum TSH, $\mu$ IU/mL, No. (\%) } & \multirow{4}{*}{0.45} \\
\hline$<0.5$ & 0 & $8(1.7)$ & \\
\hline $0.5-5$ & $79(87.8)$ & $400(86.4)$ & \\
\hline$>5$ & $11(12.2)$ & $55(11.9)$ & \\
\hline Abdominal obesity, No. (\%) & $9(10)$ & $141(30.5)$ & 0.001 \\
\hline Anemia, No. $(\%)^{f}$ & $24(29.6)$ & $66(14)$ & 0.001 \\
\hline
\end{tabular}

ing BMI, metabolic syndrome, abdominal obesity, muscle strength and age, the risk of osteoporosis remained at a significantly lower level by adjusted $\mathrm{OR}=0.31(95 \% \mathrm{CI}, 0.13$ $0.73, \mathrm{P}=0.007)($ Table 4$)$.
Abdominal obesity was significantly correlated with both FNBMD $(\mathrm{r}=0.462, \mathrm{P}=0.001)$ and LSBMD $(\mathrm{r}=0.309, \mathrm{P}$ $=0.001$ ). In subjects with abdominal obesity, the risk of osteoporosis was significantly lower as compared with those 
Table 2. Comparison of Femoral Neck (FN) and Lumbar Spine (LS) Bone Mineral Density (BMD) in Elderly Males Aged 60 Years and Older as Participants of the Amirkola Cohort Study $^{\mathrm{a}}$

\begin{tabular}{lcc}
\hline BMD Parameters & Osteoporosis $^{\mathbf{b}}$ Positive, $\mathbf{n}=\mathbf{9 0}$ & Osteoporosis Negative, $\mathbf{n}=\mathbf{4 6 3}$ \\
\hline FNBMD, $\mathbf{g r} / \mathbf{c m}^{\mathbf{2}}$ & $0.70 \pm 0.09$ & $0.93 \pm 0.12$ \\
FNBMD T-score & $-2.43 \pm 0.64$ & $-0.85 \pm 0.93$ \\
FNBMD Z-score & $-1.7 \pm 0.60$ & $-0.25 \pm 0.86$ \\
LSBMD, $\mathbf{g r} / \mathbf{c m}^{2}$ & $0.71 \pm 0.12$ & 0.001 \\
LSBMD T-score & $-2.59 \pm 0.86$ & $0.97 \pm 0.15$ \\
LSBMD Z-score & $-1.76 \pm 0.88$ & $-0.75 \pm 1.11$ \\
FNBMD, $\mathbf{g r} / \mathbf{c m}^{2}$ & $0.70 \pm 0.09$ & $-0.021 \pm 1.14$ \\
\hline
\end{tabular}

${ }^{\mathrm{a}}$ Pearson was used as appropriate with calculation of correlation coefficient.

${ }^{\mathrm{b}}$ Osteoporosis at either femoral neck or lumbar spine according to international society for clinical densitometry (ISCD) criteria.

Table 3. Correlation Coefficients Between Clinical and Biochemical Factors and Femoral Neck Bone Mineral Density (FNBMD) and Lumbar Spine Bone Mineral Density (LSBMD) in Elderly Males Above 60 Years Old Recruited From the Amirkola Cohort Study ${ }^{\mathrm{a}}$

\begin{tabular}{|c|c|c|c|c|c|c|}
\hline BMD Measurement Sites & Age & Muscle Strength, kg & BMI, $\mathrm{kg} / \mathrm{m}^{2}$ & Hemoglobin, gr/dL & Ferritin, ng/mL & Abdominal Obesity ${ }^{\mathbf{b}}$ \\
\hline FNBMD $\mathbf{~ g r} / \mathrm{cm}^{2}$ & $-0.332,0.001$ & $0.363,0.001$ & $0.565,0.001$ & $0.200,0.001$ & $0.158,0.001$ & $0.462,0.001$ \\
\hline LSBMD, $\mathbf{g r} / \mathrm{cm}^{2}$ & $-0.133,0.001$ & $0.237,0.001$ & $0.383,0.001$ & $0.125,0.003$ & $0.117,0.006$ & $0.309,0.001$ \\
\hline
\end{tabular}

${ }^{\mathrm{a}}$ Pearson with calculation of correlation coefficient.

${ }^{\mathrm{b}}$ Waist Circumference $>95 \mathrm{~cm}$.

without abdominal obesity by OR = 0.25 (95\%CI, $0.12-0.51$, $\mathrm{P}=0.009$ ) yet after correction for other clinical and biochemical confounders (Table 1), the association reached a statistically non-significant level (Table 4).

Metabolic syndrome was also associated with lower risk of osteoporosis compared to those without this syndrome. However, after adjustment for confounders (Table 1 ), the risk of osteoporosis reached a statistically nonsignificant level (Table 4).

Quadriceps muscle strength had a positive relationship with BMD at both FN and LS sites (Table 3) and muscle strength $>30 \mathrm{~kg}$ was associated with lower risk of osteoporosis compared with $<30 \mathrm{~kg}$ by OR $=0.42$ (95\% CI, 0.23 - 0.76, $\mathrm{P}=0.005$ ), and after adjustment the negative association of muscle strength and osteoporosis remained at a significant level by OR = 0.48 (95\%CI, $0.25-0.89, \mathrm{P}=0.002)$ (Table 4).

Anemia was associated with higher risk of osteoporosis as compared with patients without anemia by OR $=1.99$ (95\% CI, $1.03-3.8, \mathrm{P}=0.038$ ). In patients with history of osteoporotic fractures, the risk of osteoporosis was higher with $\mathrm{OR}=2.22(95 \% \mathrm{CI}, 1.26-3.93, \mathrm{P}=0.0006)$.

High level of education was associated with nonsignificantly lower and inhaled corticosteroids with nonsignificantly higher risk of osteoporosis (Table 4). However, high level of physical activity, vitamin D deficiency, serum level of testosterone, high serum ferritin, smoking, and subclinical hypothyroidism had no association with osteoporosis (Table 4).

\section{Discussion}

The findings of this study indicated that $16.2 \%$ of elderly males in the geographic region of northern Iran had osteoporosis at either the hip or spine region. Among several clinical, demographic and laboratory parameters, which have been investigated, factors such as diabetes, BMI, muscle strength, metabolic syndrome, abdominal obesity and educational level were positively associated with higher BMD and lower risk of osteoporosis in univariate analyses whereas anemia, inhaled corticosteroids, history of fracture and age, were associated with lower BMD and higher risk of osteoporosis in the elderly males. However, in multivariate analyses after adjustment for all covariates, only diabetes, obesity, overweight and quadriceps muscle strength were associated with lower risk of osteoporosis, while anemia and fracture history were associated with significantly higher risk of osteoporosis. Furthermore, traditional factors such as age, smoking, vitamin D deficiency, physical inactivity, which were associated with low BMD in other studies, significantly associated with osteoporosis in this study. Although the findings of this study are supported by several previously published studies, they differ with the results of other studies (7-9, 16, 19, 26-29). Several parameters including study design, age of patients, gender, ethnicity, nutrition, body habitus, lifestyle, BMD measurement sites, prevalence and distribution of the associated factors in the general population and coexistence of these conditions in patients may explain the 
Table 4. Associated Factors of Osteoporosis in Elderly Males With Calculation of Odds Ratio (OR) and Adjusted OR Using Multiple Logistic Regression Analysis ${ }^{\mathrm{a}, \mathrm{b}, \mathrm{c}}$

\begin{tabular}{|c|c|c|c|c|}
\hline Variables & Unadjusted OR & $\mathbf{P}$ & Adjusted OR & $\mathbf{P}$ \\
\hline \multicolumn{5}{|l|}{ Age, $y$} \\
\hline $60-69$ & 1 & - & - & \\
\hline$>80$ & $2.15(1.009-4.59)$ & 0.046 & $1.60(0.69-3.7)$ & 0.27 \\
\hline \multicolumn{5}{|l|}{ BMI, $\mathrm{kg} / \mathrm{m}^{2 \mathrm{~d}}$} \\
\hline$<25$ & 1 & - & 1 & \\
\hline $25-29$ & $0.20(0.11-0.36)$ & 0.001 & $0.21(0.10-0.42)$ & 0.001 \\
\hline$>30$ & $0.29(0.07-0.54)$ & 0.001 & $0.25(0.06-0.92)$ & 0.038 \\
\hline \multicolumn{5}{|l|}{ Serum vitamin $\mathrm{D}, \mathrm{ng} / \mathrm{mL}^{\mathrm{e}}$} \\
\hline$>30$ & 1 & - & 1 & - \\
\hline $20-29$ & $0.56(0.32-0.98)$ & 0.049 & $0.92(0.47-1.81)$ & 0.82 \\
\hline$<20$ & $0.61(0.35-1.07)$ & 0.095 & $1.3(0.68-2.5)$ & 0.41 \\
\hline$<3$ & 1 & - & 1 & 0.16 \\
\hline $3-10$ & $0.75(0.46-1.21)$ & 0.26 & $0.66(0.38-1.17)$ & 0.49 \\
\hline$>10$ & $0.76(0.31-1.86)$ & 0.67 & $0.69(0.25-1.94)$ & \\
\hline \multicolumn{5}{|l|}{ Education levels } \\
\hline Illiterate & 1 & 1 & 1 & \\
\hline Primary school & $0.70(0.41-1.18)$ & 0.11 & $0.86(0.47-1.58)$ & 0.63 \\
\hline High school and university & $0.30(0.11-0.77)$ & 0.004 & $0.46(0.15-1.39)$ & 0.17 \\
\hline \multicolumn{5}{|l|}{ Physical activity $^{\mathrm{g}}$} \\
\hline$>150$ vs. $<150$ & $1.05(0.57-1.94)$ & 0.87 & $0.92(0.46-1.82)$ & 0.81 \\
\hline \multicolumn{5}{|l|}{ Diabetes } \\
\hline Yes vs. NO & $0.35(0.18-0.68)$ & 0.001 & $0.31(0.13-0.73)$ & 0.007 \\
\hline \multicolumn{5}{|l|}{ Metabolic syndrome } \\
\hline Yes vs. No & $0.37(0.23-0.58)$ & 0.002 & $0.82(0.45-1.5)$ & 0.54 \\
\hline \multicolumn{5}{|l|}{ Abdominal obesity ${ }^{\text {h }}$} \\
\hline Yes vs. No & $0.25(0.12-0.51)$ & 0.009 & $0.69(0.26-1.85)$ & 0.47 \\
\hline \multicolumn{5}{|l|}{ Anemia $^{i}$} \\
\hline Yes vs. No & $2.59(1.50-4.45)$ & 0.007 & $1.99(1.03-3.8)$ & 0.038 \\
\hline \multicolumn{5}{|l|}{ Smoking } \\
\hline Yes vs. No & $0.97(0.60-1.57)$ & 0.91 & $0.82(0.46-1.45)$ & 0.51 \\
\hline \multicolumn{5}{|l|}{ History of fracture } \\
\hline Yes vs. No & $1.97(1.23-3.15)$ & 0.005 & $2.22(1.26-3.93)$ & 0.006 \\
\hline \multicolumn{5}{|l|}{ Serum ferritin ${ }^{j}$} \\
\hline$>100$ vs. $<100$ & $0.66(0.42-1.05)$ & 0.097 & $0.98(0.57-1.67)$ & 0.94 \\
\hline \multicolumn{5}{|l|}{ Quadriceps muscle } \\
\hline strength $>30 \mathrm{~kg}$ vs. $<30 \mathrm{~kg}$ & $0.42(0.23-0.76)$ & 0.005 & $0.48(0.25-0.89)$ & 0.002 \\
\hline
\end{tabular}

${ }^{a}$ Osteoporosis at either femoral neck or lumbar spine according to International society for clinical densitometry (ISCD) criteria.

${ }^{\mathrm{b}} \mathrm{Chi}$ square test with calculation of $95 \% \mathrm{CI}$.

${ }^{\mathrm{d}} \mathrm{BMD}<25 \mathrm{~kg} / \mathrm{m}^{2}=$ normal weight or underweight, 25 - 29 = overweight,$>30=$ obesity

${ }^{\mathrm{e}}$ Serum $25-\mathrm{OHD}<20 \mathrm{ng} / \mathrm{mL}=$ deficiency, $20-29.9=$ insufficiency, $>30=$ sufficiency.

${ }^{\mathrm{f}}$ Serum testosterone $<3 \mathrm{ng} / \mathrm{dL}=$ low, $3-10=$ normal, $>10=$ high.

${ }^{\mathrm{g}}$ Determined using questionnaire for daily physical activity $>150=$ high, $<150=$ low.

${ }^{\mathrm{h}} \mathrm{WC}>95 \mathrm{~cm}$.

${ }^{\mathrm{i}}$ Anemia defined as hemoglobin levels less than $13 \mathrm{gr} / \mathrm{dL}$.

${ }^{\mathrm{j}}$ Serum ferritin $>100 \mathrm{ng} / \mathrm{mL}=$ high $<100 \mathrm{ng} / \mathrm{mL}=$ low.

${ }^{\mathrm{c}}$ Multiple regression analysis with calculation of $95 \% \mathrm{CI}$. 


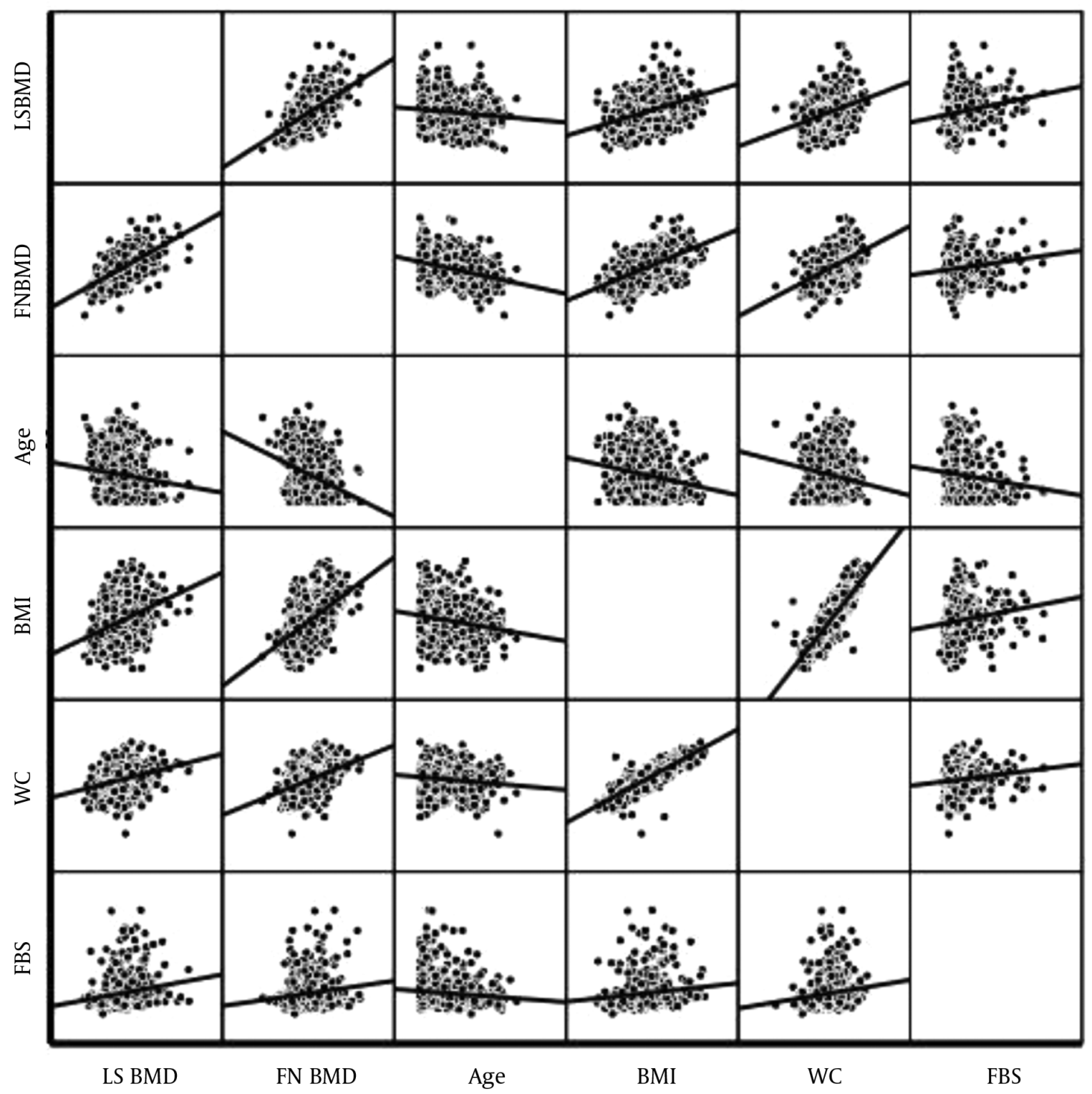

LS, lumbar spine; BMD, bone mineral density; FN, femoral neck; BMI, body mass index; WC, waist circumference $>102$ cm; FBS, fasting blood sugar.

different results between various studies.

Prevalence of osteoporosis in another Iranian population with mean age of $54.2 \pm 11.5$ years was $19.9 \%$ (30) and in a study on Danish males aged 60 - 74 years was $10.2 \%$ (27). Difference in the prevalence of osteoporosis between populations is dependent on age, patient's characteristics, and design of the study as well as the level of participation in the epidemiological studies. Oldest and sickest individuals declined to participate, which introduced an unavoidable bias. Distance and motivation may also influence response rate and the representativeness of the cohort.

Hannan et al. (9), in a meta-analysis of 167 studies found age $>70$ years, low BMI, physical inactivity, prolonged corticosteroids therapy and previous fractures as risk factors of low BMD-related fracture in males and females (26). Similar findings were reported in a longitudi- 
nal study of elderly males and females (9).

Age is an important cause of low $\operatorname{BMD}(4,9,31)$. In the present study, age was inversely correlated with low BMD and osteoporosis, but the association of age with osteoporosis decreased to a non-significant level after multivariate analyses. This issue may be explained by variations in distribution of diabetes, obesity in particular muscle strength across various age groups. While diabetes and obesity were positively distributed amongst age groups, yet prevalence of patients with high muscle strength was significantly higher in younger age groups, which explained age-related differences in osteoporosis in this study (data are not shown). Therefore, disappearance of negative association with age after multivariate analyses in this study should be attributed to removing of the positive effect of muscle strength on BMD. A significant positive correlation between muscle strength and BMD, as observed in this study, was supported by Ahedi et al. (32), who found a positive association between FNBMD and hip muscle cross-sectional area and muscle strength. It was shown that patients with greater and denser psoas muscles have greater LSBMD, and those with higher quadriceps muscles strength have greater FNBMD (28).

In the present study, BMD in diabetes was higher than non-diabetic individuals. Similar or different results have been reported in other studies (33-36), which may be ascribed to differences in age of patients, gender, ethnicity or BMD measurement site. Treatment of diabetes with metformin stimulates osteoblast differentiation and hyperinsulinemia exerts anabolic on BMD (37).

In this cohort study, BMI was positively correlated with BMD and the risk of osteoporosis was lower in subjects with higher BMI as compared with lower BMI, which is consistent with other studies (12). Rexhepi et al. (12), found an independent association between BMI and FNBMD as well as LSBMD in males and postmenopausal females. In a cross-sectional study of individuals with $\mathrm{BMI}<30 \mathrm{~kg} / \mathrm{m}^{2}$, there was a positive linear relationship between BMI and BMD up to $30 \mathrm{~kg} / \mathrm{m}^{2}$, and greater than $30 \mathrm{~kg} / \mathrm{m}^{2}$ was associated with little BMD increment (37). The association between BMI and BMD is race dependent. Castro et al. (38), in a cross-sectional study of White and African American females found that each unit increase of BMI significantly increased BMD in White females but decreased BMD in African American females.

The positive association between obesity and BMD and lower risk of osteoporosis as observed in the present study has been supported by other previous studies $(13,37)$. Beneficial effect of obesity on BMD has been attributed to loading effect of weight on bone (13). However, in obese or overweight individuals, both fat mass and lean body mass are components of weight. Visceral fat mass in obesity exerts a negative effect whereas lean mass confers a positive effect (38). In the present study, the positive effect of metabolic syndrome and abdominal obesity on BMD disappeared after adjustment. However, data regarding metabolic syndrome and BMD are conflicting $(39,40)$. Among all components of metabolic syndrome, waist circumference had the strongest correlation with lower BMD (41). Waist circumference, which is a diagnostic criteria for abdominal obesity and one major component of the metabolic syndrome, correlates with visceral fat mass (40).

In this study, anemia and history of fractures were associated with lower BMD and higher risk of osteoporosis. The relationship between anemia and osteoporosis has been attributed to proliferation of hematopoietic cells including osteoclasts, and subsequent augmentation of bone desorption (41). Meta-analysis of 11 cohorts demonstrated that prior history of fracture is associated with higher risk of subsequent fracture (42).

The results of this study should be considered with limitations. We did not find a significant association between osteoporosis and inhaled corticosteroid therapy, physical inactivity, smoking, serum vitamin D deficiency and low serum testosterone. However, the results in this context are controversial across different studies. The association between smoking and osteoporosis is dose-dependent and observed mainly in heavy smokers (43). Similarly, data regarding the dosage and duration of inhaled corticosteroids therapy were not provided. Nonetheless, our previous study did not show a significant bone loss in inhaled corticosteroid users amongst asthmatic patients aged $>$ 50 years old (44). The lack of association between osteoporosis and vitamin D deficiency, low physical activity and low level of education in this cohort may be attributed to coexistence of one or more associated factors such as diabetes, obesity and anemia, in patients or inadequate sample size in some subgroups. These factors may differently affect BMD and confound the results. In this study, mean serum vitamin D was $30 \mathrm{ng} / \mathrm{mL}$. However, sufficient levels of serum vitamin D were observed in $38.9 \%$ of patients with osteoporosis and $27.4 \%$ of those without osteoporosis, which seems to be unusual in this age group. However, data in this context are self-reported and prior injection of vitamin D cannot be ignored. Nevertheless, these findings are comparable with the general population of this geographic region (45).

The strength of the study is dependent on characteristics of the cohort, which is comprised of subjects with homogenous characteristics regarding lifestyle, socio demographic characteristics, ethnicity and nutrition. All male inhabitants of a small town aged 60 years and older, who participated in BMD measurement, were recruited and thus the cohort is expected to be representative of the 
general population. In addition the sample size was large enough to give the results adequate power.

\subsection{Conclusion}

The findings of this study indicate that in the geographic region of northern Iran, obesity, BMI, muscle strength and diabetes correlate positively with BMD and are associated with lower risk of osteoporosis in elderly males whereas, anemia and history of previous fractures are negatively correlated with BMD and higher risk of osteoporosis. Nonetheless, the associations of other demographic and clinical parameters like abdominal obesity, metabolic syndrome, level of education, physical activity, inhaled corticosteroids therapy, and smoking with BMD did not reach a statistical level. The design of this study was cross-sectional and the findings did not indicate causality. This issue needs a prospective longitudinal study.

\section{Acknowledgments}

We thank the clinical research development unit of Rouhani hospital, Babol University of Medical Sciences for assistance in case discussions and editing of the article.

\section{References}

1. Bliuc D, Nguyen ND, Alarkawi D, Nguyen TV, Eisman JA, Center JR. Accelerated bone loss and increased post-fracture mortality in elderly women and men. Osteoporos Int. 2015;26(4):1331-9. doi: 10.1007/s00198-014-3014-9. [PubMed: 25600473].

2. Sidlauskas KM, Sutton EE, Biddle MA. Osteoporosis in men: epidemiology and treatment with denosumab. Clin Interv Aging. 2014;9:593-601. doi: 10.2147/CIA.S51940. [PubMed: 24748777].

3. Berger C, Langsetmo L, Joseph L, Hanley DA, Davison KS, Josse R, et al. Change in bone mineral density as a function of age in women and men and association with the use of antiresorptive agents. CMAJ. 2008;178(13):1660-8. doi: 10.1503/cmaj.071416. [PubMed:18559803].

4. Center JR, Nguyen TV, Schneider D, Sambrook PN, Eisman JA. Mortality after all major types of osteoporotic fracture in men and women: an observational study. Lancet. 1999;353(9156):878-82. doi:10.1016/S01406736(98)09075-8. [PubMed: 10093980].

5. Poor G, Atkinson EJ, Lewallen DG, O'Fallon WM, Melton L3. Age-related hip fractures in men: clinical spectrum and short-term outcomes. Osteoporos Int. 1995;5(6):419-26. doi: 10.1007/BF01626602. [PubMed 8695962].

6. Khosla S, Melton LJ 3rd, Atkinson EJ, O'Fallon WM. Relationship of serum sex steroid levels to longitudinal changes in bone density in young versus elderly men. J Clin Endocrinol Metab. 2001;86(8):3555-61. doi: 10.1210/jcem.86.8.7736. [PubMed: 11502778].

7. Cauley JA, Ewing SK, Taylor BC, Fink HA, Ensrud KE, Bauer DC, et al. Sex steroid hormones in older men: longitudinal associations with 4.5-year change in hip bone mineral density-the osteoporotic fractures in men study. J Clin Endocrinol Metab. 2010;95(9):4314-23. doi: 10.1210/jc.2009-2635. [PubMed: 20554716].

8. Bours SP, van Geel TA, Geusens PP, Janssen MJ, Janzing HM, Hoffland GA, et al. Contributors to secondary osteoporosis and metabolic bone diseases in patients presenting with a clinical fracture. J Clin Endocrinol Metab. 2011;96(5):1360-7. doi: 10.1210/jc.2010-2135. [PubMed 21411547].
9. Hannan MT, Felson DT, Dawson-Hughes B, Tucker KL, Cupples LA, Wilson PW, et al. Risk factors for longitudinal bone loss in elderly men and women: the Framingham Osteoporosis Study. J Bone Miner Res. 2000;15(4):710-20. doi: 10.1359/jbmr.2000.15.4.710. [PubMed: 10780863].

10. Kenny AM, Prestwood KM, Marcello KM, Raisz LG. Determinants of bone density in healthy older men with low testosterone levels. J Gerontol A Biol Sci Med Sci. 2000;55(9):492-7. doi: 10.1093/gerona/55.9.M492. [PubMed: 10995046].

11. Montagnani A, Gonnelli S, Alessandri M, Nuti R. Osteoporosis and risk of fracture in patients with diabetes: an update. Aging Clin Exp Res. 2011;23(2):84-90. doi:10.1007/BF03351073. [PubMed: 21743287].

12. Rexhepi S, Bahtiri E, Rexhepi M, Sahatciu-Meka V, Rexhepi B. Association of Body Weight and Body Mass Index with Bone Mineral Density in Women and Men from Kosovo. Mater Sociomed. 2015;27(4):259-62. doi: 10.5455/msm.2015.27.259-262. [PubMed: 26543419].

13. Felson DT, Zhang Y, Hannan MT, Anderson JJ. Effects of weight and body mass index on bone mineral density in men and women: the Framingham study. J Bone Miner Res. 1993;8(5):567-73. doi: 10.1002/jbmr.5650080507. [PubMed: 8511983]

14. Nielson CM, Marshall LM, Adams AL, LeBlanc ES, Cawthon PM, Ensrud $\mathrm{K}$, et al. BMI and fracture risk in older men: the osteoporotic fractures in men study (MrOS). J Bone Miner Res. 2011;26(3):496-502. doi: 10.1002/jbmr.235. [PubMed: 20814955].

15. Chan MY, Frost SA, Center JR, Eisman JA, Nguyen TV. Relationship between body mass index and fracture risk is mediated by bone mineral density. J Bone Miner Res. 2014;29(11):2327-35. doi: 10.1002/jbmr.2288. [PubMed: 24862213].

16. Kao WH, Kammerer CM, Schneider JL, Bauer RL, Mitchell BD. Type 2 diabetes is associated with increased bone mineral density in MexicanAmerican women. Arch Med Res. 2003;34(5):399-406. [PubMed: 14602507].

17. Irani AD, Poorolajal J, Khalilian A, Esmailnasab N, Cheraghi Z. Prevalence of osteoporosis in Iran: A meta-analysis. J Res Med Sci. 2013;18(9):759-66. [PubMed: 24381618].

18. Ranjbar Omrani G, Masoompour M, Hamidi A, Mardanifard HA, Taghavi M, Talezadeh P. Bone mineral density in the normal Iranian population: a comparison with American reference data. Arch Osteoporos. 2006;1(1-2):29-35. doi:10.1007/s11657-006-0005-2.

19. Heidari B, Hosseini R, Javadian Y, Bijani A, Sateri MH, Nouroddini HG. Factors affecting bone mineral density in postmenopausal women. Arch Osteoporos. 2015;10:15. doi: 10.1007/s11657-015-0217-4. [PubMed: 25972061].

20. Hajian-Tilaki KO, Heidari B. Prevalence of obesity, central obesity and the associated factors in urban population aged 20-70 years, in the north of Iran: a population-based study and regression approach. Obes Rev. 2007;8(1):3-10. doi: 10.1111/j.1467-789X.2006.00235.x. [PubMed: 17212790].

21. Hajian-Tilaki K, Heidari B. Prevalences of overweight and obesity and their association with physical activity pattern among Iranian adolescents aged 12-17 years. Public Health Nutr. 2012;15(12):2246-52. doi: 10.1017/S1368980012001048. [PubMed: 22578771].

22. Hajian-Tilaki K, Heidari B, Firouzjahi A, Bagherzadeh M, Hajian-Tilaki A, Halalkhor S. Prevalence of metabolic syndrome and the association with socio-demographic characteristics and physical activity in urban population of Iranian adults: a population-based study. Diabetes Metab Syndr. 2014;8(3):170-6. doi: 10.1016/j.dsx.2014.04.012. [PubMed: 25220921].

23. Hosseini SR, Cumming RG, Kheirkhah F, Nooreddini H, Baiani M, Mikaniki E, et al. Cohort profile: the Amirkola Health and Ageing Project (AHAP). Int J Epidemiol. 2014;43(5):1393-400. doi: 10.1093/ije/dyt089. [PubMed: 23918798].

24. Heidari B, Heidari P, Tilaki KH. Relationship between unexplained arthralgia and vitamin D deficiency: a case control study. Acta Med Iran. 2014;52(5):400-5. [PubMed: 24902022]. 
25. Hans D, Downs RW, Duboeuf F, Greenspan S, Jankowski LG, Kiebzak GM, et al. Skeletal sites for osteoporosis diagnosis: the 2005 ISCD Official Positions. J Clin Densitom. 2006;9(1):15-21. doi: 10.1016/j.jocd.2006.05.003. [PubMed: 16731427].

26. Liu H, Paige NM, Goldzweig CL, Wong E, Zhou A, Suttorp MJ, et al. Screening for osteoporosis in men: a systematic review for an American College of Physicians guideline. Ann Intern Med. 2008;148(9):685701. [PubMed: 18458282].

27. Frost M, Wraae K, Abrahamsen B, Hoiberg M, Hagen C, Andersen M, et al. Osteoporosis and vertebral fractures in men aged 60-74 years. Age Ageing. 2012;41(2):171-7. doi: 10.1093/ageing/afr170. [PubMed: 22232302].

28. Neville CE, Murray LJ, Boreham CA, Gallagher AM, Twisk J, Robson PJ, et al. Relationship between physical activity and bone mineral status in young adults: the Northern Ireland Young Hearts Project. Bone. 2002;30(5):792-8. doi: 10.1016/S8756-3282(02)00711-1. [PubMed: 11996922].

29. Chin KY, Nirwana S, Mohamed I, Ahmad F, Ramli E, Aminuddin A. The association between bone health indicated by calcaneal quantitative ultrasound and metabolic syndrome in Malaysian men.JDiabetes Metab Disord. 2015;14(9) doi:10.1186/s40200-015-0136-3.

30. Ghafoori S, Keshtkar A, Khashayar P, Ebrahimi M, Ramezani M, Mohammadi Z, et al. The risk of osteoporotic fractures and its associating risk factors according to the FRAX model in the Iranian patients: a follow-up cohort. J Diabetes Metab Disord. 2014;13(1):93. doi: 10.1186/s40200-014-0093-2. [PubMed: 25349839].

31. Wraae KAB, Hoiberg M, Hagen C, Andersen M, Brixen K. Osteoporosis and vertebral fractures in men aged 60-74 years. Aging. 2012;41:171-7.

32. Ahedi H, Aitken D, Scott D, Blizzard L, Cicuttini F, Jones G. The association between hip muscle cross-sectional area, muscle strength, and bone mineral density. Calcif Tissue Int. 2014;95(1):64-72. doi: 10.1007/s00223-014-9863-6. [PubMed: 24829114].

33. Akeroyd JM, Suarez EA, Bartali B, Chiu GR, Yang M, Schwartz AV, et al. Differences in skeletal and non-skeletal factors in a diverse sample of men with and without type 2 diabetes mellitus. J Diabetes Complications. 2014;28(5):679-83. doi:10.1016/j.jdiacomp.2014.05.007. [PubMed: 24973938].

34. Leidig-Bruckner G, Ziegler R. Diabetes mellitus a risk for osteoporosis?. Experiment Clin Endocrinol Diabetes. 2001;109(2):493-514.

35. Leidig-Bruckner G, Grobholz S, Bruckner T, Scheidt-Nave C, Nawroth $\mathrm{P}$, Schneider JG. Prevalence and determinants of osteoporosis in patients with type 1 and type 2 diabetes mellitus. BMC Endocr Disord.
2014;14:33. doi: 10.1186/1472-6823-14-33. [PubMed: 24721668].

36. Majima T, Komatsu Y, Yamada T, Koike Y, Shigemoto M, Takagi C, et al. Decreased bone mineral density at the distal radius, but not at the lumbar spine or the femoral neck, in Japanese type 2 diabetic patients. Osteoporos Int. 2005;16(8):907-13. doi: 10.1007/s00198-0041786-z. [PubMed: 15558237].

37. Yan W, Li X. Impact of diabetes and its treatments on skeletal diseases. Front Med. 2013;7(1):81-90. doi: 10.1007/s11684-013-0243-9. [PubMed: 23377889].

38. Castro JP, Joseph LA, Shin JJ, Arora SK, Nicasio J, Shatzkes J. Differential effect of obesity on bone mineral density in White, Hispanic and African American women: a cross sectional study. Nutr Metab. 2005;2(9).

39. Boyanov M, Bakalov D, Boneva Z. Bone mineral density in men with and without the metabolic syndrome. Aging Male. 2009;12(2-3):62-5. doi: 10.1080/13685530903150812. [PubMed: 19639517].

40. Kim HY, Choe JW, Kim HK, Bae SJ, Kim BJ, Lee SH, et al. Negative association between metabolic syndrome and bone mineral density in Koreans, especially in men. Calcif Tissue Int. 2010;86(5):350-8. doi: 10.1007/s00223-010-9347-2. [PubMed: 20354685].

41. Nobrega da Silva V, Goldberg TB, Mosca LN, Bisi Rizzo Ada C, Teixeira Ados S, Corrente JE. Metabolic syndrome reduces bone mineral density in overweight adolescents. Bone. 2014;66:1-7. doi: 10.1016/j.bone.2014.05.011. [PubMed: 24875293].

42. Kanis JA, Johnell O, De Laet C, Johansson H, Oden A, Delmas P, et al. A meta-analysis of previous fracture and subsequent fracture risk. Bone. 2004;35(2):375-82. doi: 10.1016/j.bone.2004.03.024. [PubMed: 15268886].

43. Tamaki J, Iki M, Fujita Y, Kouda K, Yura A, Kadowaki E, et al. Impact of smoking on bone mineral density and bone metabolism in elderly men: the Fujiwara-kyo Osteoporosis Risk in Men (FORMEN) study. Osteoporos Int. 2011;22(1):133-41. doi:10.1007/s00198-010-1238-x. [PubMed: 20383631].

44. Monadi M, Javadian Y, Cheraghi M, Heidari B, Amiri M. Impact of treatment with inhaled corticosteroids on bone mineral density of patients with asthma: related with age. Osteoporos Int. 2015;26(7):2013-8. doi: 10.1007/s00198-015-3089-y. [PubMed: 25860975].

45. Heidari B, Heidari P, Hajian-Tilaki K. Association between serum vitamin D deficiency and knee osteoarthritis. Int Orthop. 2011;35(11):162731. doi: 10.1007/s00264-010-1186-2. [PubMed: 21191580]. 